\title{
Human species and mating systems: Neandertal-Homo sapiens reproductive isolation and the archaeological and fossil records
}

\author{
Karenleigh A. Overmann \& Frederick L. Coolidge \\ Psychology Department, University of Colorado, 1420 Austin Bluffs Parkway, Colorado Springs, CO \\ 80918, USA \\ e-mail: koverman@uccs.edu
}

\begin{abstract}
Summary - The present paper examined the assumption of strong reproductive isolation (RI) between Homo neanderthalensis and Homo sapiens, as well as the question of what form it might have taken, using insights from the parallel case of chimpanzee-bonobo hybridization. RI from hybrid sterility or inviability was thought unlikely based on the short separation-to-introgression timeline. The forms of RI that typically develop in primates have relatively short timelines (especially for partial implementation); they generally preclude mating or influence hybrid survival and reproduction in certain contexts, and they have the potential to skew introgression directionality. These RI barriers are also consistent with some interpretations of the archaeological and fossil records, especially when behavioral, cognitive, morphological, and genetic differences between the two human species are taken into consideration. Differences potentially influencing patterns of survival and reproduction include interspecies violence, Neandertal xenophobia, provisioning behavior, and ontogenetic, morphological, and behavioral differences affecting matters such as kin and mate recognition, infanticide, and sexual selection. These factors may have skewed the occurrence of interbreeding or the survival and reproduction of hybrids in a way that might at least partially explain the pattern of introgression.
\end{abstract}

Keywords - Hybridization, Speciation, Introgression.

\section{Introduction}

Comparison of Neandertal and modern human biparentally inherited nuclear DNA has been interpreted as demonstrating unidirectional gene flow from Neandertals to some modern human populations; this contrasts with data from uniparentally inherited DNA (mitochondrial DNA and Y-chromosome markers), which show no evidence of introgression (Gibbons, 2010; Green et al., 2010; Wall et al., 2009; Yotova et al., 2011). Recent theoretical models, over a range of demographic parameters, have indicated that these genetic patterns are predicted if successful interbreeding events were rare; with evidence of some period of coexistence, this implies that the
RI barriers between them must have been strong (Currat \& Excoffier, 2011; Neves \& Serva, 2012).

One theoretical model postulating strong reproductive isolation (RI) between $H$. neanderthalensis and H. sapiens is that of Currat et al. (2008), who noted that introgressive genes typically flow from local to invading species in plants and animals; on this view, gene flow simply followed the general pattern in introgressing from resident Neandertals to early modern humans expanding out of Africa. Even a small introduction of local alleles would have the potential to reach relatively high frequencies because introduction at the inception of the invasion, no matter how small the total period of interspecies contact, would have the potential to proliferate 
the alleles widely as a function of demographic change (Currat et al., 2008; Durand et al., 2011; Sankararaman et al., 2012); the H. sapiens population was increasing while that of $H$. neanderthalensis was decreasing (Green et al., 2010; Mellars \& French, 2011). Other factors may also have intervened. As Bruner (2013) noted, early modern humans and Neandertals may have interbred "to such a negligible degree that evolution and selection did not care" (p. 12); further, the phenomenon of local extinctions could have resulted in some interbreeding events leaving traces in the genome while others did not (Green et al., 2010).

While the population genetics explanation is sufficient to explain the pattern of introgression, Currat et al. (2008) acknowledged that their model could not explain all cases, since it was insensitive to complicating factors (e.g., selection functions, preferences and biases, and behaviors) and assumed uniform parameters (e.g., territorial carrying capacities; rates of migration and interbreeding) that might not hold in all cases or across single cases over time. Several plausible alternatives have also been proposed: Eriksson \& Manica (2013) interpreted genetic similarities as reflecting ancient population structure rather than hybridization, though SánchezQuinto et al. (2012) and Yang et al. (2009) have argued that a scenario involving distinct African subpopulations was unlikely. Gokcumen et al. (2013) suggested that divergent haplogroups mimic the admixture signature, implying that any introgression would have occurred before the two human species diverged. Another a hypothesis is that of Pinhasi et al. (2011) and Wood et al. (2013), who interpreted recent site dating analyses as indicating a minimal contact period; if this is correct, the introgression discussion will need to incorporate a significantly reduced window of opportunity (especially for Europe), which would nonetheless be compatible with the population genetics explanation. Others have noted that the period of coexistence may have been extensive, possibly exceeding 10,000 years (Currat \& Excoffier, 2004; Hublin et al., 2012), with the result that the two human species may have been constantly in contact, particularly in locations such as the Near East (i.e., at the borders of or the overlap between the two ranges).

Assuming that admixture did occur and that the interpretation of unidirectional introgression is correct (matters still under debate), the implication would be that the two human species were reproductively isolated to a significant degree. The implication of strong RI is interesting and warrants further examination; the question of what form RI between the two human species might have taken was therefore examined in light of general primate RI tendencies. Future avenues of research were also suggested for the archaeological and fossil records and contemporary primatology, consistent with the RI tendencies of primates, especially baboons (because of their frequent hybridization) and chimpanzees and bonobos (because of their genetic similarity to Neandertals and modern humans).

\section{Previous proposals on RI form}

\section{Hybrid sterility}

Mason \& Short (2011) proposed that the pattern of introgression may demonstrate Haldane's rule, in which interspecies genetic interactions yield differential sex ratios and unisexual sterility in hybrid offspring (Haldane, 1922). The syndrome has been observed in insects, birds, and mammals; in some species, female hybrids are not produced at all, are produced infrequently, or are sterile if produced, and in others, the syndrome affects male offspring (Coyne, 1985; Haldane, 1922). Such inviability or infertility of male hybrids may at least partially explain the apparent lack of Y-chromosome introgression the two human species (Mason \& Short, 2011). Mason \& Short (2011) have also suggested that the only fertile hybrids were female offspring with $H$. neanderthalensis fathers and $H$. sapiens mothers. However, the timeline between $H$. neanderthalensis- $H$. sapiens separation and introgression is relatively short: Their divergence has been estimated to have occurred at a maximum of 500,000 years ago and perhaps as recently as 440,000-270,000 years ago (Green et al., 2006, 2010). The average time for developing hybrid 
sterility in mammals is less than 2.0 to 4.0 million years (Fitzpatrick, 2004; Wu, 1992), a period of time at least double that separating the two human species. Mason \& Short's (2011) hypothesis would therefore require the onset of hybrid sterility to have been particularly rapid. Thus, hybrid infertility appeared unlikely to have been the form of RI isolating the two human species.

\section{Other hypotheses}

Neves \& Serva (2012) suggested that $H$. neanderthalensis and $H$. sapiens were reproductively isolated through cultural or social differences, and Schillachi \& Froehlich (2001) proposed that the two human species might have had trouble recognizing each other as suitable mates. Currat \& Excoffier (2011) also suggested that the two were reproductively isolated through lower hybrid fitness; the unidirectionality of the introgression suggests that hybrid fitness may have been context-dependent. Together, these analyzes suggest examining archaeological and fossil records, as well as hybridization in other primates, for evidence of possible behavioral, cognitive, and morphological differences with the potential to have reproductively isolated the two species.

\section{The chimpanzee-bonobo model and its extensibility}

Hybridization between chimpanzees and bonobos was considered on the premise that their case was sufficiently similar to that of $H$. neanderthalensis and $H$. sapiens to illuminate their potential for and form of RI. Chimpanzees and bonobos (Pan troglodytes and P. paniscus, respectively) are the closest genetic relatives of $H$. neanderthalensis and $H$. sapiens (Green et al., 2010). The small genetic distance between them suggests that they could be considered a single species, as has been suggested for $H$. sapiens and H. neanderthalensis, who are also known as Homo sapiens neanderthalensis (e.g., Curnoe \& Thorne, 2003; Tattersall \& Schwartz, 1999; Wegmann \& Excoffier, 2010; the debate on this has persisted for well over a century despite the abundance of
Neandertal and early modern human remains available for comparison; see Bruner, 2013). The genetic similarity between the two species pairs suggests that hybridization would have been likely for both, given geographic proximity (see the discussion of syngameons, closely related species that hybridize frequently, in Holliday, 2003).

The timelines and reasons for speciation are parallel between the two species pairs. Chimpanzees and bonobos speciated less than a million years ago, a timeline roughly comparable to that separating Neandertals and early modern humans (Green et al., 2006, 2010; Hey, 2009). Both speciation events may have occurred through geographic isolation: Chimpanzees and bonobos are thought to have been separated by the Congo River, which remains impassible today to their relatively poor ability to swim (Matsuzawa, 2006). This is analogous to the circumstances believed to have separated the $H$. heidelbergensis populations ancestral to $H$. sapiens and $H$. neanderthalensis, who were also geographically isolated, perhaps by climate change (e.g., Gipps, 1991).

Chimpanzees and bonobos differ morphologically and behaviorally, and early modern humans and Neandertals might have as well. Morphological differences are subtle, with bonobos being perhaps more paedomorphic (or juvenilized) than chimpanzees; paedomorphy represents the combined effect of heterochronic change in the speed (slowed), onset (late), or duration (shortened) of ontogenetic growth, with the result that descendant adults resemble the ancestral juvenile condition (McKinney, 2000; Schlesinger, 2008; Shea, 1983a,b). H. sapiens were similarly paedomorphic relative to $H$. neanderthalensis, who may have matured more quickly and been more robust (BenItzhak et al., 2005; Gunz et al., 2010; Lieberman et al., 2007; Smith et al., 2010). Behavioral distinctions between chimpanzees and bonobos are more overt and include more than three dozen behaviors, such as cooperation, dispersal patterns, dominance, social structures, provisioning, territoriality, tolerance, and mating (Hare et al., 2007; Parish \& de Waal, 2006; Prüfer et al., 2012). H. neanderthalensis and $H$. sapiens may also have differed in behaviors such as provisioning, diet, tool production, art, and 
group size (Kuhn \& Stiner, 2006; Lalueza-Fox et al., 2011; Richards et al., 2009; Spikins et al., 2010; Wynn \& Coolidge, 2012). The idea that the two human species differed behaviorally is controversial (e.g., Villa \& Soriano, 2010; Zilhão et al., 2010), especially since the complexity of the Levallois technique, the use of compound technology, and the very fact of their long-term survival across wide geographic and climatic ranges argue in favor of Neandertal competency (Roebroeks \& Villa, 2011; Schlanger, 1996; Stewart, 2005). Nonetheless, comparative cranial morphologies and emerging genetic evidence (discussed below) suggest that the two human species may have differed cognitively, implying that there would have been behavioral differences as well.

There are several limitations to the chimpanzee-bonobo model that constrain its extensibility to the two human species. The first is that the morphological, behavioral, and cognitive differences between chimpanzees and bonobos appear more subtle than those distinguishing Neandertals and early modern humans, possibly because the former inhabit similar subtropical niches, while the latter inhabited divergent environments, with Neandertals becoming coldadapted (Conard, 2011). A second limitation of the model is that the nonhuman pair is distinctcognitively, morphologically, and behaviorallyfrom the human pair, so that the parallels extend only so far. A third limitation in the model arises from the debate on whether $H$. sapiens and $H$. neanderthalensis differed to any significant degree. That is, interpretations of the archaeological record as showing no differences between the two human species argue against RI resulting from morphological, behavioral, or cognitive differences, while interpretations of the archaeological record as demonstrating differences argue in favor of RI.

\section{RI and hybridization}

RI can be prezygotic or postzygotic (respectively, either before or after a zygote is formed). In prezygotic RI, the formation of hybrid zygotes is prevented, either before or after mating occurs, because species are isolated geographically (i.e., no proximity), temporally (no synchronization of activity or mating cycles), behaviorally (no recognition of mate suitability), mechanically (no fit between genitalia), or chemically (inability to tolerate another species' reproductive environment) (Nosil, 2012; Wiens, 2004). In comparison, in postzygotic RI, hybrids are formed but have lower fitness, either in any environment or as a function of their ecological circumstance. Lower hybrid fitness in any environment would include cases in which genomic incompatibility precluded successful embryonic development, as well as instances of Haldane's rule (Haldane, 1922). Lower hybrid fitness in certain environments would include cases in which hybrid survival and reproduction were increased or decreased through factors present in their environmental situation.

\section{Prezygotic RI}

In primates, speciation through prezygotic isolation requires an average of 1.1 million years (Curnoe et al., 2006). This is slightly longer than the chimpanzee-bonobo speciation timeline and at least double that of $H$. neanderthalensis and $H$. sapiens, suggesting that given the opportunity both species pairs might interbreed, as is indeed the case with captive chimpanzees and bonobos (Curnoe \& Thorne, 2003; Vervaecke \& Van Elsacker, 1992). Notably, RI through prezygotic isolation may be the norm for primates (Curnoe et al., 2006); the circumstance that chimpanzees and bonobos have not been separated long enough to develop it suggests either that $H$. neanderthalensis and $H$. sapiens were not separated long enough to develop this form of RI, or that their differences (e.g., behavioral, morphological) were significant (and thus might be detectable in the archaeological record).

\section{Postzygotic RI}

In mammals, RI from hybrid inviability requires, on average, between 2.0 and 4.0 million years to develop (Fitzpatrick, 2004), at least twice that of prezygotic RI. This average implies that neither species pair would have been 
reproductively isolated by hybrid inviability, since both have shorter timelines. In fact, chimpanzees and bonobos produce "apparently normal" hybrids (Curnoe \& Thorne, 2003, p. 211), suggesting that Neandertals and early modern humans might have as well. Certainly, other primate species (particularly baboons) produce fertile hybrids (e.g., Papio hamadryas and Theropithecus gelada; see Dunbar \& Dunbar, 1974; Jolly et al., 1997; Markarjan et al., 1974), though the hybrids can also be less successful reproductively, perhaps as the result of subtle morphological or behavioral differences (Jolly, 2009).

RI through hybrid sterility may require less than 2.0 to 4.0 million years to develop in mammals; assessments are complicated by the fact that hybrid sterility falls on a continuum from partial to complete (Wu, 1992). An example is the case of horses and donkeys, whose speciation occurred roughly 3.9 million years ago (based on molecular data; see Vilà et al., 2001). Female horse-donkey offspring, known as mules and hinnys, are usuallybut not invariably-sterile (Rong et al., 1988; Rong et al., 1985). This suggests that the development of hybrid sterility in horses and donkeys is nearly complete, in affecting all male and most female hybrids, but nonetheless falls short of being total. This state was reached in four times the amount of time separating bonobos from chimpanzees and eight (or more) times that separating Neandertals and early modern humans. Thus, even if primates developed hybrid sterility at an accelerated rate relative to mammals (which they are not known to do), there may still have been insufficient time for it to have developed in $H$. neanderthalensis $-H$. sapiens hybrids. The idea that the time was insufficient is further reinforced by the circumstance that chimpanzee-bonobo hybrids are probably fertile, something that is difficult to confirm because of legal restrictions on their breeding (Vervaecke, personal communication).

\section{RI variation}

Since RI through hybrid sterility exists on a continuum (Wu, 1992), other forms of RI may as well, possibly accounting for some of the insufficiencies in the speciation timeline. That is, though it appears there may have been insufficient time for Neandertals and early modern humans to develop different forms of RI in a full and complete manner, there may have been sufficient time for them to develop RI barriers in a partial or incomplete fashion, especially for prezygotic mechanisms requiring shorter development times. Partial RI implementation has a characteristic signature of being skewed since it precludes only some of the possible outcomes of interbreeding while allowing others. Thus, the specific position on the development continuum (from none to complete) might have influenced introgression directionality through some unevenness of effect, an assumption more parsimonious than assuming uniformity across all possible cross-match and circumstantial variations.

\section{Hybridization}

Hybridization is common among primates generally and may have occurred between ancestral chimpanzees and the hominin lineage following speciation from the last common ancestor (Aguiar et al., 2008; Patterson et al., 2006; Zinner et al., 2011). This suggests that the willingness to breed across species might characterize both descendent lineages, a supposition confirmed by the fact that chimpanzees and bonobos will interbreed in captivity (Curnoe \& Thorne, 2003; Vervaecke \& Van Elsacker, 1992). The morphology of primate hybrids is highly variable but generally intermediate between that of the two parent species; morphs can range from being indistinguishable from either parent species (cryptic), in between the two (intermediate), or outside the range of variation of either (unusual) (Ackerman, 2010; Zinner et al., 2011). In addition to morphological intermediacy, behavioral intermediacy has been observed in mammal hybrids (e.g., Weber et al., 2013). Notably, chimpanzee-bonobo hybrids are characterized by both morphological and behavioral intermediacy (Vervaecke, personal communication). In general, some hybrids are more vigorous, some less, than the two parent species (Ackerman, 2010); chimpanzee-bonobo hybrids have been described as having normal vitality, though this 
observation relates to circumstances of captivity (Curnoe \& Thorne, 2003). By extension, $H$. neanderthalensis $-H$. sapiens hybrids might have had morphological and behavioral characteristics that were generally intermediate between their two parent species, and while their vitality might have been normal, it could also have been a factor in their ability to respond to specific environmental conditions.

\section{Forms of RI observed in primates}

Prezygotic RI (the primate norm; see Curnoe et al., 2006) and lower hybrid fitness (postzygotic $\mathrm{RI}$ ) have been observed in primate hybridization (Aguiar et al., 2008). Asymmetric gene flow from postzygotic RI has also been observed in primates (e.g., Macaca mulatta and M. fascicularis; see Stevison \& Kohn, 2009), with behavior (e.g., philopatry; dispersal) and social group structure influencing gene flow and population structure (Tung et al., 2010). These RI barriers and influences, coupled with a timeline that may preclude the development of RI between $H$. neanderthalensis and $H$. sapiens in any form but especially in the forms of hybrid inviability and sterility, suggests that if the two human species were reproductively isolated, the form it might have taken would have followed these primate tendencies. That is, if $H$. neanderthalensis and $H$. sapiens were reproductively isolated, it may have been through behaviors that prevented the occurrence of mating, through lower hybrid fitness if mating did occur, or both.

\section{Interbreeding between \\ $H$. neanderthalensis and $H$. sapiens}

The question posed by the chimpanzeebonobo model, in which interbreeding between species is common (at least in captivity) and productive (in terms of hybrid vitality and possibly hybrid fertility as well), is why interbreeding between $H$. neanderthalensis and $H$. sapiens would have been rare once the populations reencountered one another (Currat \& Excoffier, 2011; Currat et al., 2008; Neves \& Serva, 2012). The assumption of strong $\mathrm{RI}$ is curious given that the genetic distance between the two human species was smaller than that between some modern human populations (Curnoe \& Thorne, 2003; Neves \& Serva, 2012). Behavioral, cognitive, and morphological differences do not prevent chimpanzees and bonobos from interbreeding, at least under the choice-restricted circumstances of captivity, or from producing hybrids of apparent normality, as assessed against the artificial conditions of captivity (Curnoe \& Thorne, 2003; Vervaecke \& Van Elsacker, 1992). In addition, the four chimpanzee subspecies - P. t. schweinfurthii, P. t. troglodytes, P. $t$. vellurosus, and $P$. t. verus - are similarly isolated by geography and differentiated by their behavior and morphology; however, they are known to interbreed both in the wild and in captivity and have been said to do so in all combinations (Becquet \& Przeworski, 2007; Fischer et al., 2004; Gagneux et al., 2001; Hey, 2010; Matsuzawa, 2006; Won \& Hey, 2010). These circumstances suggest either that the differences between Neandertals and early modern humans were more profound than those distinguishing chimpanzees and bonobos (precluding mating), or that interbreeding between the two human species was common but factors such as higher hybrid morality influenced hybrid survival and reproduction and hence the directionality of the introgression-or both, since the two are not mutually exclusive.

Apparently no barrier to interbreeding, chimpanzee-bonobo behavioral differences nonetheless imply cognitive differences between the two nonhuman species; for example, the greater 'patience' of bonobos relative to chimpanzees implies a difference in inhibition, an executive function (Rosati et al., 2007). These cognitive differences are consistent with the endocranial differences between the two species, which result from the divergent ontogenetic trajectories followed by each (Durrleman et al., 2012; Mitteroecker et al., 2005). The assumption that cognition may have similarly distinguished $H$. neanderthalensis and $H$. sapiens may not be unwarranted, given that morphometric differences in their fossil endocasts imply differences in cognitive domains such as language, spatiality, and creativity (e.g., Bruner, 2004, 2010; Bruner et al., 2003; Coolidge \& 
Wynn, 2013; Gunz et al., 2010; Lieberman et al., 2002; Pearce et al., 2013). The idea that there were differences in cognitive functioning is consistent with archaeological interpretations of behavioral differences (e.g., Coolidge \& Wynn, 2001, 2004; Henshilwood \& Marean, 2003; Mellars, 2004; Wynn \& Coolidge, 2004, 2012).

\section{Anatomic evidence with cognitive implications}

Morphometric comparison of $H$. neanderthalensis and $H$. sapiens endocasts reveals differences in asymmetry, the relative size and shape of the major lobes, and the cerebellum. Greater frontal-temporal encephalization and differential asymmetry patterns in $H$. sapiens suggest a language advantage for that species, enabling more effective communication between individuals (social cooperation) and across time (cultural learning) (Gunz et al., 2010; Lieberman et al., 2002;). Frontal lobe volume appears relatively equal between the two species (Bruner \& Holloway, 2010), so differences in executive functioning cannot be determined by morphometric analysis and endocast comparison alone. However, differential executive functioning may reflect differential neural reorganization subsequent to encephalization (both human species) or globularization (H. sapiens only) (Coolidge \& Wynn, 2001).

Bruner and colleagues (Bruner, 2004, 2010; Bruner et al., 2003) have suggested that parietal change may be the characteristic that truly distinguishes the two human species: The parietal region of early modern humans has an expansion (probably in the intraparietal sulcus, medial region, or upper cortex) not found in Neandertals. Parietal expansion has been associated with globularization, neural reorganization, and enhanced parietal functioning, including multimodal processing, visuospatial and sensory integration, planning and manipulation of motor sequences, control of fingers, spatial analysis, and the creation of 'inner space' representations of external space (Bruner, 2004, 2010; Bruner et al., 2003). Thus, parietal change may have contributed to the adaptive success of $H$. sapiens through improved multimodal integration, visuospatial integration, and social functioning (Holloway, 1996) or by contributing to higher-level capabilities for symbolism (Coolidge \& Overmann, 2012).

The $H$. sapiens cerebellum may also have differed. Weaver (2005) found mean cerebellum volume to be absolutely and relatively higher in modern $H$. sapiens than in $H$. neanderthalensis, and further, a derived cerebellar quotient (cerebellum/overall brain volume) was also larger in $H$. sapiens than in $H$. neanderthalensis (however, a caveat is in order: Weaver's study involved small samples, limited metrics, and straightforward statistical analyses). Every major lobe of the cortex projects through the pons to the cerebellum, and the cerebellum through the thalamus reciprocally connects to at least 14 neocortical sites. While early theories of cerebellar function proposed that motor learning and fine motor control were key attributes, recent research has clearly established that the cerebellum has an important role in nonmotor cognitive functions as well, particularly with its interconnections to the prefrontal cortices and to the parietal lobes. Balsters et al. (2013) demonstrated that cerebellar lobules (Crus I \& II) have prefrontal-projecting connections activated when processing first- and second-order cognitive (non-motor) instructions. Weaver (2005) further argued that cerebellar development in $H$. sapiens may have provided greater computational efficiency and adaptive ability. Koziol et al. (2010) attributed greater speed of adaptation and behavioral mastery and refinement to cerebellar development, and Vandervert $(2009,2011)$ attributed creativity, giftedness, and the neural basis for child prodigies to the efficiency and nature of the cerebrum-cerebellar loops. The smaller Neandertal cerebellum may therefore imply a difference in creativity, which would be consistent with archaeological interpretations suggesting behavioral differences between the two human species (e.g., Coolidge \& Wynn, 2001, 2004, 2005; Wynn \& Coolidge, 2002, 2004, 2012).

Pearce et al. (2013) also noted that the larger portion of the Neandertal brain dedicated to vision implied both a visual difference at higher latitudes and a corresponding reduction in the size of other brain regions; the relative resizing of nonoccipital regions of the Neandertal brain implies 
concomitant differences in their cognitive functionality because of the relationship between brain region size and functionality (Striedter, 2005).

\section{Genetic evidence with cognitive implications}

Emerging genetic evidence suggests there were at least subtle differences in the cognitive abilities of $H$. neanderthalensis and $H$. sapiens: Paixão-Côrtes et al. (2013) found nine non-synonymous substitutions (i.e., substitutions resulting in biological change and therefore subject to natural selection) in genes implicated in various forms of learning and memory; these imply that the two human species may have differed in these cognitive domains, as has been suggested by Wynn \& Coolidge (2004). The nine non-synonymous substitutions were $10 \%$ of 93 alleles examined in the study; Neandertal data for another $27 \%$ were missing, admitting the possibility that additional genetic changes with cognitive implications may be found. While the $10 \%$ difference presently identified would not decrease, were the missing data to vary at the same rate, the difference would show a minor increase $(12 \%)$ but could increase to as much as $37 \%$ in the unlikely case that all 25 cases of missing data differed. In view of studies showing that a single gene can significantly alter the brain (e.g., Bakircioglu et al., 2011), the study by Paixáo-Côrtes et al. (2013) suggested that the genetic differences identified (plus any additional instances identified once the missing Neandertal data have been established) should be investigated for their impact on cognition, learning, and memory, especially short-term and visual memory, cognitive abilities potentially affected by the contribution and interaction of seven or more non-synonymous substitutions.

\section{Behaviors in the archaeological record and other primates}

Anatomic and genetic evidence of potential cognitive differences between Neandertals and early modern humans are consistent with archaeological interpretations of behavioral differences between the two human species, differences with the potential to contribute to RI. Behaviors and behavioral differences that possibly acted to reduce or preclude interbreeding are suggested by evidence of intergroup violence, Neandertal xenophobia, and differential provisioning and dispersal. As shown in Table 1, intergroup violence and Neandertal xenophobia might have reduced the likelihood of interbreeding across the board, and differences in provisioning behavior might have increased the likelihood of interbreeding between $H$. neanderthalensis males and $H$. sapiens females. The effect of dispersal pattern differences was uncertain.

\section{Intergroup violence}

As "many kinds of primates are intolerant of strangers," a factor in the formation of breeding groups (Erwin, 1986, p. 297), interspecies violence related to territoriality might have discouraged contact between groups, thereby reducing mating opportunities. While baboons do not appear to be particularly territorial (Cowlishaw, 1995; Howell \& Bourlière, 2008), wild chimpanzees have been known to engage in cooperative defense and even patrol their territories, influencing female reproductive behavior (Mitani \& Watts, 2005; Mitani et al., 2010; Williams et al., 2004; Williams et al., 2004; Wilson et al., 2001). Violent contact between the two human species is suggested by Shanidar-3, the Neandertal skeleton from Shanidar, Iraq whose ninth rib is lesioned in a way that would be consistent with the projectile weapons of early modern humans (Churchill et al., 2009; Santamaria et al., 2010); actuarial support for weapons producing similar wounds cannot, however, be taken as proof that Neandertals and early modern humans were in contact, let alone in conflict. However, some interpretations of the archaeological evidence have suggested that whatever contact limitations were in place at the beginning of the coexistence period may have improved toward its end, based on Neandertal techno-cultural changes that imply prolonged, amiable contact with early modern humans (Green et al., 2006; Hublin et al., 1996; but also see Higham et al., 2010, who highlight the challenges of establishing clear associations between artifacts and their makers). 


\section{Neandertal xenophobia}

An aspect of group-level intolerance of strangers is that of possible Neandertal reluctance to approach strangers (xenophobia), which might have reduced the likelihood of their approaching human individuals for any reason, including mating. The characterization of Neandertals as shy is based on archaeological evidence of their living in small groups and generally lacking exotic raw materials at their sites, factors interpreted by some scholars as suggesting that Neandertals may have had difficulty managing numerous face-to-face contacts and relatively restricted territorial mobility that imply possible cognitive constraints on sociality and spatiality, respectively (FernándezLaso et al., 2011; Gamble, 2011; Gamble et al., 2011; García-Antón et al., 2011; Lalueza-Fox et al., 2011; Wynn \& Coolidge, 2004, 2012). However, this possible influence on interbreeding must be tempered by the insight that Neandertals may not have been as territorially restricted as once thought; for example, recent evidence of diet and raw material exploitation suggests that they may have exploited larger territories and had less restricted diets than previously believed (Richards et al., 2008, 2009; Spinapolice, 2012).

\section{Provisioning behaviors}

Communal hunting by Neandertals, with gathering plus gendered division of labor by early modern humans (Kuhn \& Stiner, 2006; Richards et al., 2009), imply differential opportunities for mating and conspecific interference, factors that could have reduced or prevented interbreeding. That is, the inclusion of both Neandertal males and females in hunting groups suggests that both sexes were less likely to be unaccompanied and thus less likely to be in situations in which mating could occur, whether opportunistic or coercive (Buss, 2007). By comparison, human males engaged in hunting may have been more likely unaccompanied or have had group dominance advantages that would facilitate mating, while human females engaged in gathering would more likely have been unaccompanied or in female-only situations in which conspecific male
Tab. 1 - Influence of differential behavior and morphology.

\begin{tabular}{lll}
\hline $\begin{array}{l}\text { POTENTIAL } \\
\text { INFLUENCE ON RI }\end{array}$ & $\begin{array}{l}\text { F: } \boldsymbol{H n ;} \\
\mathbf{M}: \boldsymbol{H s}\end{array}$ & $\begin{array}{l}\text { F: } \boldsymbol{H s ;} \\
\mathbf{M}: \boldsymbol{H n}\end{array}$ \\
\hline Behavior & & \\
\hline Intergroup Violence & Reduce & Reduce \\
\hline Neandertal Xenophobia & Reduce & Reduce \\
\hline Provisioning & Increase & Reduce \\
\hline Dispersal & Uncertain & Uncertain \\
\hline
\end{tabular}

\begin{tabular}{lll} 
Morphology & & \\
Ontogenetic Differences & Increase & Uncertain \\
\hline Sexual Selection & Increase & Reduce \\
\hline
\end{tabular}

Note - Key: F = Father; $\mathrm{M}=$ Mother; $H n=H$. neanderthalensis; $H s=H$. sapiens. The overall pattern suggested an increased likelihood of interbreeding between $H$. neanderthalensis males and $H$. sapiens females and a reduced likelihood of interbreeding between $H$. neanderthalensis females and $H$. sapiens males.

interference and protection would have been less likely, as remains the case in modern situations (e.g., Koshen, 2007). Conspecific interference is certainly a behavior observed in wild chimpanzees (e.g., Williams et al., 2004). However, the inclusion of gathering as a provisioning strategy by Neandertals (Hardy et al., 2012) and the phenomenon of $H$. sapiens female hunting in modern hunter-gatherer societies (Kuhn \& Stiner, 2006) suggest that there may have been a significant amount of commonality in the provisioning behaviors of both human species, with the result that the contribution of behavioral differences in provisioning to RI requires further examination.

\section{Dispersal patterns}

Differences in age- or sex- based dispersal patterns may have affected the occurrence of interbreeding. For age, dispersal-pattern differences have been noted in baboon hybrids ( $P$. anubis and P. cynocephalus; see Alberts \& Altmann, 2001), suggesting that $H$. neanderthalensis $-H$. 
sapiens hybrids may have dispersed at a different age than non-hybrids. Regarding sex-based differences, Neandertals may have been male philopatric, a primate social system in which males remain in their natal range while females reaching sexual maturity emigrate to new groups (Lalueza-Fox et al., 2011). Genetic evidence supporting this hypothesis derives from 12 Neandertal remains at El Sidrón, Asturias, Spain, which show three different maternal lineages for all 12 individuals but the same mitochondrial DNA for the three adult males (but also see Vigilant \& Langergraber, 2011, who argue that this evidence is inconclusive at best). In comparison, $70 \%$ of all modern human societies are patrilocal (a related and fairly synonymous term for a social system in which married females reside with their husband's family; the terms may be differentiated along lines of humans [patrilocal] and nonhumans [male philopatry]; see Chapais, 2008). The rate for $H$. sapiens has been estimated by some researchers as greater than that of modern chimpanzees, which are strongly biased toward male philopatry and female dispersal (Hashimoto et al., 2008; Langergraber et al., 2007; Matsuzawa, 2006). However, Parish $\&$ de Waal (2006) have reported lower estimates of patrilocality for humans and have suggested that there is no typical pattern of female dispersal for hunter-gatherers. Differences in the degree of philopatry between the two human species might therefore have had the potential to skew the pattern of interbreeding.

\section{Morphology in the fossil record and other primates}

The morphological differences between the two human species seen in fossils may have influenced mate recognition through factors of ontogenetic development and sexual selection; this is distinct from the idea of trying to recognize hybrid morphology in fossils (Holliday, 2003). As shown in Table 1, ontogenetic differences and sexual selection may have provided possible advantages for $H$. neanderthalensis males.

\section{Mate recognition and ontogenetic differences}

Neandertals may have matured faster (and thus earlier), based on evidence showing that they had shorter periods of dental development than was typical for early modern humans (Smith et al., 2010; but also see Guatelli-Steinberg et al., 2005, who note that Neandertal dental growth rates fall within the human range). Cranial development may have differed as well, with $H$. sapiens developing a more globular brain shape postnatally that implies a longer period of neural reorganization than would have been the case for $H$. neanderthalensis, who lacked postnatal globularization (Gunz et al., 2010). This suggested that brain development (and thus immaturity) would have been prolonged in $H$. sapiens relative to $H$. neanderthalensis (however, also see Ponce de León et al., 2008, who suggest that brain growth rates were similar in both human species). These potential differences in maturity, if substantiated by future studies, might have been a factor in dispersal patterns and mate recognition, enhanced for the earlier-maturing Neandertals and degraded for later-maturing early modern humans. Such is the case for hybrid baboons, with hybrids of both sexes maturing and dispersing earlier, resulting in a selective advantage for hybrid males (advantages for female hybrids are offset by other social and environmental factors; see Alberts \& Altmann, 2001; Charpentier et al., 2008; Tung et al., 2008).

\section{Mate recognition and sexual selection}

As previously noted, $H$. sapiens were paedomorphic relative to $H$. neanderthalensis, who were characterized by greater muscle mass and bone strength (Ben-Itzhak et al., 2005; Gunz et al., 2010; Lieberman et al., 2007; Smith et al., 2010). These physiological differences might have influenced mate recognition, especially in female choice: $H$. neanderthalensis females might have interpreted paedomorphic $H$. sapiens males as having unsuitable youthfulness or lower fitness, thereby reducing their recognition as suitable mates. It is also possible that $H$. sapiens females might have interpreted the earlier maturing, 
more robust $H$. neanderthalensis male form as indicating suitability for mating and higher fitness. A similar pattern might be predicted for chimpanzees and bonobos (i.e., that there would be female selection differences depending on the particular combination of paedomorphic vs. robust species); however, the literature on chimpanzee-bonobo hybridization does not address whether this has been observed, and in any case the influence of captivity on opportunity and choice would have to be considered as well. The effect has been observed in macaques, however, with introgression "biased strongly" toward $M$. mulatta males (the larger species) and $M$. fascicularis females (the smaller species), either because the females prefer the larger males or because the larger males can more easily coerce sex (Stevison \& Kohn, 2009, p. 2470), biases that might also have also characterized Neandertal males and early modern human females (see Mason \& Short, 2011, who note the strength differential). The tendency is also found in baboon hybrids: $P$. hamadryas and $P$. Anubis hybrid males have a phenotype that is apparently more attractive to females (Nystrom, 1992).

\section{Hybrid fitness mediated by context}

Morphological and behavioral intermediacy for $H$. neanderthalensis $-H$. sapiens hybrids may have influenced the directionality of introgression by reducing their fitness or by reducing mate or kin recognition. As shown in Table 2, intermediacy in hybrid morphology possibly provided an advantage to hybrids among early modern humans but a disadvantage for hybrids among the Neandertals. In addition, uncertain paternity, hybrid behavioral intermediacy, or weakened kin recognition might have reduced hybrid survival in either situation.

\section{Lower survival outcomes from intermediate hybrid} morphology

Fossil trauma patterns suggest that the Neandertal led an arduous, dangerous lifestyle that included close-in hunting of large animals
Tab. 2 - Influence on hybrid fitness.

\begin{tabular}{lll}
\hline $\begin{array}{l}\text { POTENTIAL } \\
\text { INFLUENCE } \\
\text { ON RI }\end{array}$ & $\begin{array}{l}\text { HYBRIDS } \\
\text { AMONG } \\
\text { H. sapiens }\end{array}$ & $\begin{array}{l}\text { HYBRIDS AMONG } \\
\text { H. neanderthalensis }\end{array}$ \\
\hline $\begin{array}{l}\text { Survival } \\
\text { (Morphology) }\end{array}$ & Increase & Reduce \\
\hline $\begin{array}{l}\text { Infanticide } \\
\begin{array}{l}\text { Survival } \\
\text { (Behavior) }\end{array}\end{array}$ & Reduce & Reduce \\
\hline $\begin{array}{l}\text { Kin } \\
\text { Recognition }\end{array}$ & Reduce & Reduce \\
\hline
\end{tabular}

Note - The overall pattern suggested that hybrids might have had a slightly better chance of surviving among $H$. sapiens than among $H$. neanderthalensis.

and megaherbivores (e.g., mammoth, wooly rhinoceros); the combination caused severe, often fatal injuries (Berger \& Trinkaus, 1995; Bocherens, 2011; Gaudzinski-Windheuser \& Roebroeks, 2011). The trauma patterns are consistent with other fossil evidence of young-old differentials suggestive of early mortality for Neandertal adults and a generally high rate of mortality for Neandertal infants (Pettitt, 2000; Richter, 2001; Trinkaus, 1995, 2011). Given the intermediate morphology of chimpanzee-bonobo hybrids, it is likely that $H$. neanderthalensis $-H$. sapiens hybrids would also have taken an intermediate form as well (consistent with the variability noted by Ackerman, 2010). In general, hybrids might have been less robust in terms of muscle mass and bone strength than was typical for Neandertals but stronger and more robust than usual for early modern humans (Ben-Itzhak et al., 2005), a potential disadvantage for hybrids among the Neandertals but a potential advantage among early modern humans, possibly influencing the direction of introgression.

\section{Infanticide}

Intermediate and unusual (but possibly not cryptic) hybrids on both sides might have been subjected to infanticide, a consequence of the greater likelihood of their being recognized as 
having uncertain paternity (a significant cause of infanticide across primate species; see HiraiwaHasegawa, 1988) or to reduce the competition for resources (Hrdy, 1979). The latter may have been particularly true for non-cryptic hybrids among the Neandertals, given the range of potential factors contributing to the species' demographic decline and eventual extinction. Infanticide has been practiced by many human groups, including contemporary ones, and has been observed in modern chimpanzees, where it has been interpreted as the result of male aggression, pathological female cannibalism for the sake of nutritional advantage, or the selection of particularly vulnerable targets during inter-group violence (Sherrow \& Amsler, 2007; Townsend et al., 2007). Male aggression against infants has also been observed in baboons (Cowlishaw, 1995). The greater likelihood of being subject to infanticide might have reduced hybrid survival in both groups, especially among the Neandertals.

\section{Lower survival outcomes from intermediate hybrid behavior}

Hybrid males, assuming they survived past infancy, might have been more aggressive than the norm (hybrid behavioral intermediacy) or less able to inhibit aggressive impulses (hybrid cognitive intermediacy), creating situations of early mortality through risky behavior, or exile or attack from an inability of the group to tolerate abnormal levels of behaviors such as aggression. Such behaviors and consequences are known among modern chimpanzees and humans (e.g., Nishida, 2004; Nishida et al., 1995; Townsend et al., 2007; Wrangham \& Peterson, 1996), implying that they might also have characterized the Neandertals as well. Behavioral comparisons of chimpanzees and bonobos suggests that bonobos, the more paedomorphic species, are less aggressive and display greater inhibition (an executive function) than chimpanzees (Hare et al., 2007; Parish \& de Waal, 2006; Prüfer et al., 2012; Rosati et al., 2007). A comparison of the cognitive capabilities of Neandertals and early modern humans suggests that the latter may have had similar advantages in executive functioning, including inhibition (Coolidge \& Wynn, 2001, 2004, 2005; Wynn \& Coolidge, 2002, 2004, 2012), a possible factor in hybrid survival. However, while cognitive differences can be inferred from the morphological comparison of fossils, similar inferences of behavioral differences from archaeological remains are open to interpretation. Nonetheless, the greater rate of traumatic injury in Neandertals might be consistent with higher levels of risk-taking, suggesting that hybrid behavioral variability could have been a survival factor.

\section{Reduced mate and kin recognition}

Another potential outcome of hybrid intermediacy might have been reduced mate and kin recognition, which has been observed in primate hybrids (e.g., Bradley \& Mundy, 2008; Jolly, 2009). For example, P. hamadryas interbreeds with $M$. mulatta, but the resultant hybrids are less reproductively successful, either because they are not recognized as suitable mates or they are infertile (Jolly, 2001, 2009; Markarjan et al., 1997). Across primate species, mechanisms used for mate and kin recognition include phenotypic matching and behavioral cues (Silk, 2005; Strier, 2004), mechanisms potentially weakened by hybrid morphological and behavioral variability and possibly exacerbated by Neandertal xenophobia. The likelihood of survival might have been decreased further by the demands of the Neandertal lifestyle, especially given the lack of older individuals available to assist with provisioning and infant care (Trinkaus, 1995, 2011); among $H$. sapiens, these conditions were perhaps not as severe, with the result that the likelihood of survival may have been marginally better.

\section{Conclusions}

The pattern of introgression detected in comparison of the $H$. neanderthalensis and $H$. sapiens genomes (Green et al., 2010) may not have been the result of hybrid sterility (Mason \& Short, 2011) because of the insufficient amount of time between the separation and reunion of the two 
human species, nor of hybrid inviability, which requires at least as much time (if not more) to instantiate. However, introgression directionality could have been influenced by forms of RI that are typical for primates-specifically, prezygotic (premating) isolation and postzygotic survival and reproduction differentials-given two assumptions: first, that behavioral, morphological, and cognitive differences (which are consistent with emerging genetic evidence) were sufficient to influence matters such as mate recognition and sexual selection; second, that hybrid intermediacy was sufficient to influence survival and reproduction outcomes. While these RI mechanisms may have skewed the pattern of interbreeding and hybrid survival and reproduction, all of them require a more in-depth examination of the archaeological and fossil records, as well as comparisons with modern primate species that hybridize (especially baboons, chimpanzees, and bonobos). If interbreeding between the two human species was more likely to have involved $H$. neanderthalensis males and $H$. sapiens females, and survival and reproduction outcomes were better for hybrids among early modern humans but lower for hybrids among the Neandertals, these factors may be apparent from the archaeological and fossil records, as well as tendencies observed in contemporary primate species.

A limitation of the present review was that it assumed that hybrids would remain with their natal groups to interbreed with the species raising them if they survived to sexual maturity and were recognized as suitable mates. It is of course possible that hybrids might not have remained with their natal groups, instead moving between groups of different species, perhaps with greater ease and acceptance than might have been the case for non-hybrids. However, this possibility reflects a level of granularity seldom reached in fossil analysis, since hybrid phenotypes are difficult to disambiguate from inter-individual variation (Ackerman, 2010). Observational data from nonhuman primates might determine whether hybrid acceptance varies across primate groups generally, though the reduced reproductive success of hybrids (Jolly, 2009) suggests a decreased acceptance within natal groups that might extend to non-natal groups as well. A second limitation of the review was that the effect of hybrid gender on survival and reproduction was not considered in detail, something future studies might address.

\section{Acknowledgements}

We are grateful for the contributions of Jeremy Bono, Professor of Biology at the University of Colorado, Colorado Springs, who reviewed early drafts of this article, and Dr. Emiliano Bruner and three anonymous referees, whose close and critical review of the manuscript led to significant improvements in it.

\section{References}

Ackerman R.R. 2010. Phenotypic traits of primate hybrids: recognizing admixture in the fossil record. Evol. Anthropol., 19: 258-270.

Aguiar L.M., Pie M.R. \& Passos F.C. 2008. Wild mixed groups of howler species (Alouatta caraya and Alouatta clamitans) and new evidence for their hybridization. Primates, 49: 149-152.

Alberts S.C. \& Altmann J. 2001. Immigration and hybridization patterns of yellow and anubis baboons in and around Amboseli, Kenya. Am. J. Primatol., 53: 139-154.

Balsters J.H., Whelan C.D., Robertson I.H. \& Ramnani N. 2013. Cerebellum and cognition: evidence for the encoding of higher order rules. Cereb. Cortex, 23: 1433-1443.

Bakircioglu M., Carvalho O.P., Khurshid M., Cox J.J., Tuysuz B., Barak T., Yilmaz S., Caglayan O., Dincer A., Nicholas A.K., Quarrell O., Springell K., Karbani G., Malik S., Gannon C., Sheridan E., Crosier M., Lisgo S.N., Lindsay S., Bilguvar K., Gergely F., Gunel M. \& Woods C.G. 2011. The essential role of centrosomal NDE1 in human cerebral cortex neurogenesis. Am. J. Hum. Genet., 88: 1-13.

Becquet C. \& Przeworski M. 2007. A new approach to estimate parameters of speciation models with application to apes. Genome Res., 17: 1505-1519. 
Ben-Itzhak S., Smith P. \& Bloom R.A. 2005. Radiographic study of the humerus in Neandertals and $H$. sapiens sapiens. Am. J. Phys. Anthropol., 77: 231-242.

Berger T.D. \& Trinkaus E. 1995. Patterns of trauma among the Neandertals. J. Archaeol. Sci., 22: 841-852.

Bocherens H. 2011. Diet and ecology of Neanderthals: implications from $\mathrm{C}$ and $\mathrm{N}$ isotopes: insights from bone and tooth biogeochemistry. In N.J. Conard \& J. Richter (eds): Neanderthal Lifeways, Subsistence and Technology: One Hundred Fifty Years of Neanderthal Study, pp. 73-86. Springer, Dordrecht.

Bradley B.J. \& Mundy N.I. 2008. The primate palette: the evolution of primate coloration. Evol. Anthropol., 17: 97-111.

Bruner E. 2004. Geometric morphometrics and paleoneurology: brain shape evolution in the genus Homo. J. Hum. Evol., 47: 279-303.

Bruner E. 2010. Morphological differences in the parietal lobes within the human genus: a neurofunctional perspective. Curr. Anthropol., 51: S77-S88.

Bruner E., Manzi G. \& Arsuaga J.L. 2003. Encephalization and allometric trajectories in the genus Homo: evidence from the Neandertal and modern lineages. Proc. Natl. Acad. Sci. U.S.A., 100: 15335-15340.

Bruner E. 2013. The species concept as a cognitive tool for biological anthropology. Am. J. Primatol., 75: 10-15.

Buss D.M. 2007. Mating strategies: consequences for conflict and cooperation. In S.W. Gangestad \& J.A. Simpson (eds): The Evolution of Mind: Fundamental Questions and Controversies, pp. 375-382. Guilford Press, New York.

Chapais B. 2008. Primeval kinship: how pair-bonding gave birth to human society. The President and Fellows of Harvard College, Cambridge.

Churchill S.E., Franciscus R.G., McKean-Peraza H.A., Daniel J.A. \& Warren B.R. 2009. Shanidar 3 Neandertal rib puncture wound and paleolithic weaponry. J. Hum. Evol., 57: 163-178.

Conard N.J. 2011. The demise of the Neanderthal cultural niche and the beginning of the Upper
Paleolithic in Southwestern Germany. In N.J. Conard \& J. Richter (eds): Neanderthal Lifeways, Subsistence and Technology: One Hundred Fifty Years of Neanderthal Study, pp. 223-240. Springer, Dordrecht.

Coolidge F.L. \& Overmann K.A. 2012. Numerosity, abstraction, and the emergence of symbolic thinking. Curr. Anthropol., 53: 204-225.

Coolidge F.L. \& Wynn T. 2001. Executive functions of the frontal lobes and the evolutionary ascendancy of $H$. sapiens. Camb. Archaeol. J., 11: 255-260.

Coolidge F.L. \& Wynn T. 2004. A cognitive and neuropsychological perspective on the Châtelperronian. J. Anthropol. Res., 60: 55-73.

Coolidge F.L. \& Wynn T. 2005. Working memory, its executive functions, and the emergence of modern thinking. Camb. Archaeol. J., 15: 5-26.

Cowlishaw G. 1995. Behavioural patterns in baboon group encounters: the role of resource competition and male reproductive strategies. Behaviour, 132, 75-86.

Coyne J.A. 1985. The genetic basis of Haldane's rule. Nature, 314: 736-738.

Curnoe D. \& Thorne A. 2003. Number of ancestral human species: a molecular perspective. Homo, 53: 201-224.

Curnoe D., Thorne A. \& Coate J.A. 2006. Timing and tempo of primate speciation. J. Evol. Biol., 19: 59-65.

Currat M. \& Excoffier L. 2004. Modern humans did not admix with Neanderthals during their range expansion into Europe. PLoS Biol., 2: 2264-2274.

Currat M. \& Excoffier L. 2011. Strong reproductive isolation between humans and Neanderthals inferred from observed patterns of introgression. Proc. Natl. Acad. Sci. U.S.A., 108: 15129-15134.

Currat M., Ruedi M., Petit R.J. \& Excoffier L. 2008. The hidden side of invasions: massive introgression by local genes. Evolution, 62: 1908-1920.

Dunbar R.I.M. \& Dunbar E.P. 1974. Ecological relations and niche separation between sympatric terrestrial primates in Ethiopia. Folia Primatol., 1, 36-60. 
Durand E.Y., Patterson N., Reich D. \& Slatkin M. 2011. Testing for ancient admixture between closely related populations. Mol. Biol. Evol., 28: 2239-2252.

Durrleman S., Pennec X., Trouvé A., Ayache N. \& Braga J. 2012. Comparison of the endocranial ontogenies between chimpanzees and bonobos via temporal regression and spatiotemporal registration. J. Hum. Evol., 62: 74-88.

Eriksson A. \& Manica A. 2012. Effect of ancient population structure on the degree of polymorphism shared between modern human populations and ancient hominins. Proc. Natl. Acad. Sci. U.S.A., 109: 13956-13960.

Erwin J. 1986. Environments for captive propagation of primates: interaction of social and physical factors. In K. Benirschke (ed): Primates: The Road to Self-sustaining Populations, pp. 297305. Springer-Verlag, New York.

Fernández-Laso M.C., Navarro M.G.C., GarcíaAntón M.D. \& Rivals F. 2011. Territorial mobility of Neanderthal groups: a case study from Level M of Abric Romaní (Capellades, Barcelona, Spain). In N.J. Conard \& J. Richter (eds): Neanderthal Lifeways, Subsistence and Technology: One Hundred Fifty Years of Neanderthal Study, pp. 187-202. Springer, Dordrecht.

Fischer A., Wiebe V., Pääbo S. \& Przeworski M. 2004. Evidence for a complex demographic history of chimpanzees. Mol. Biol. Evol., 21: 799-808.

Fitzpatrick B.M. 2004. Rates of evolution of hybrid inviability in birds and mammals. Evolution, 58: 1865-1870.

Gagneux P., Gonder M.K., Goldberg T.L. \& Morin P.A. 2001. Gene flow in wild chimpanzee populations: What genetic data tell us about chimpanzee movement over space and time. Philos. T. Roy. Soc. B, 356: 889-897.

Gamble C. 2011. The social and material life of Neanderthals. In N.J. Conard \& J. Richter (eds): Neanderthal Lifeways, Subsistence and Technology: One Hundred Fifty Years of Neanderthal Study, pp. 157-166. Springer, Dordrecht.

Gamble C., Gowlett J. \& Dunbar R. 2011. The social brain and the shape of the Palaeolithic. Camb. Archaeol. J., 21: 115-136.
García-Antón M.D., Granda L.M. \& Navarro M.G.C. 2011. Level G of Las Fuentes de San Cristóbal (Southern Pyrenees, Spain): availability of lithic resources and territory management. In N.J. Conard \& J. Richter (eds): Neanderthal Lifeways, Subsistence and Technology: One Hundred Fifty Years of Neanderthal Study, pp. 203-219. Springer, Dordrecht.

Gaudzinski-Windheuser S. \& Roebroeks W. 2011. On Neanderthal subsistence in last interglacial forested environments in Northern Europe. In N.J. Conard \& J. Richter (eds): Neanderthal Lifeways, Subsistence and Technology: One Hundred Fifty Years of Neanderthal Study, pp. 61-71. Springer, Dordrecht.

Gibbons A. 2010. Close encounters of the prehistoric kind. Science, 328: 680-684.

Gipps J. 1991. Skulls and human evolution: the use of casts of anthropoid skulls in teaching concepts of human evolution. J. Biol. Educ., 25: 283-291.

Gokcumen O., Zhu Q., Mulder L.C.F., Iskow R.C., Austermann C., Scharer C.D., Raj T., Boss J.M, Sunyaev S., Price A., Stranger B., Simon V. \& Lee C. 2013. Balancing selection on a regulatory region exhibiting ancient variation that predates human-Neandertal divergence. PLoS Genet., 9: 1-12.

Green R.E., Krause J., Briggs A.W., Maricic T., Stenzel U., Kircher M., Patterson N., Li H., Zhai W., Fritz M.H., Hansen N.F., Durand E.Y., Malaspinas A.S., Jensen J.D., Marques-Bonet T., Alkan C., Prüfer K., Meyer M., Burbano H.A., Good J.M., Schultz R., Aximu-Petri A., Butthof A., Höber B., Höffner B., Siegemund M., Weihmann A., Nusbaum C., Lander E.S., Russ C., Novod N., Affourtit J., Egholm M., Verna C., Rudan P., Brajkovic D., Kucan Z., Gusic I., Doronichev V.B., Golovanova L.V., Lalueza-Fox C., de la Rasilla M., Fortea J., Rosas A., Schmitz R.W., Johnson P.L., Eichler E.E., Falush D., Birney E., Mullikin J.C., Slatkin M., Nielsen R., Kelso J., Lachmann M., Reich D. \& Pääbo S. 2010. A draft sequence of the Neandertal genome. Science, 328: 710-722.

Green R.E., Krause J., Ptak S.E., Briggs A.W., Ronan M.T., Simons J.F., Du L., Egholm M., Rothberg J.M., Paunovic M. \& Pääbo 
S. 2006. Analysis of one million base pairs of Neanderthal DNA. Nature, 444: 330-336.

Guatelli-Steinberg D., Reid D.J., Bishop T.A., Larsen C.S. \& Trinkaus E. 2005. Anterior tooth growth periods in Neandertals were comparable to those of modern humans. Proc. Natl. Acad. Sci. U.S.A., 102: 14197-14202.

Gunz P., Neubauer S., Maureille B. \& Hublin J.-J. 2010. Brain development after birth differs between Neanderthals and modern humans. Curr. Biol., 20: R921-R922.

Haldane J.B.S. 1922. Sex ratios and unisexual sterility in hybrid animals. J. Genet., 12: 101-109. Hardy K., Buckley S., Collins M.J., Estalrrich A., Brothwell D., Copeland L, García-Tabernero A., García-Vargas S., de la Rasilla M., LaluezaFox C., Huguet R., Bastir M., Santamaría D., Madella M., Wilson J., Cortés A.F. \& Rosas A. 2012. Neanderthal medics? Evidence for food, cooking, and medicinal plants entrapped in dental calculus. Naturwissenschaften, 99: 617-626.

Hare B., Melis A.P., Woods V., Hastings S. \& Wrangham R. 2007. Tolerance allows bonobos to outperform chimpanzees on a cooperative task. Curr. Biol., 17: 619-623.

Hashimoto C., Tashiro Y., Hibino E., Mulavwa M., Yangozene K., Furuichi T., Idani G. \& Takenaka O. 2008. Longitudinal structure of a unit-group of bonobos: male philopatry and possible fusion of unit-groups. In T. Furuichi \& J. Thompson (eds): The Bonobos: Behavior, Ecology, and Conservation, pp. 107-119. Springer, New York.

Henshilwood C.S. \& Marean C.W. 2003. The origin of modern human behavior: critique of the models and their test implications. Curr. Anthropol., 44: 627-651.

Hey J. 2010. The divergence of chimpanzee species and subspecies as revealed in multipopulation isolation-with-migration analyses. Mol. Biol. Evol., 27: 921-933.

Higham T., Jacobi R., Julien M., David F., Basell L., Wood R., Davies W. \& Ramsey C.B. 2010. Chronology of the Grotte du Renne (France) and implications for the context of ornaments and human remains within the
Châtelperronian. Proc. Natl. Acad. Sci. U.S.A., 107: 20234-20239.

Hiraiwa-Hasegawa M. 1988. Adaptive significance of infanticide in primates. Tree, 3: 102-105.

Holliday T.W. 2003. Species concepts, reticulation, and human evolution. Curr. Anthropol., 44, 653-673.

Holloway R.L. 1996. Toward a synthetic theory of human brain evolution. In J.P. Changeaux \& J. Chavaillon (eds): Origins of the Human Brain, pp. 42-54. Clarendon Press, Oxford.

Howell F.C. \& Bourlière F. (eds) 2008. African ecology and human evolution. Translation, New Brunswick, NJ.

Hrdy S.B. 1979. Infanticide among animals: a review, classification, and examination of the implications for the reproductive strategies of females. Ethol. Sociobiol., I: 13-40.

Hublin J.-J., Spoor F., Braun M., Zonneveld F. \& Condemi S. 1996. A late Neanderthal associated with Upper Palaeolithic artefacts. Nature, 381: 224-226.

Hublin J.-J., Talamo S., Julien M., David F., Connet N., Bodu P., Vandermeersch B. \& Richards M.P. 2012. Radiocarbon dates from the Grotte du Renne and Saint-Césaire support a Neandertal origin for the Châtelperronian. Proc. Natl. Acad. Sci. U.S.A., 109: 18743-18748.

Jolly C.J. 2001. A proper study for mankind: Analogies from the Papionin monkeys and their implications for human evolution. Yearb. Phys. Anthropol., 44: 177-204.

Jolly C.J. 2009. Fifty years of looking at human evolution: backward, forward, and sideways. Curr. Anthropol., 50: 187-199.

Jolly C.J., Woolley-Barker T., Beyene S., Disotell T.R. \& Phillips-Conroy J.E. 1997. Intergeneric hybrid baboons. Int. J. Primatol., 18: 597-627.

Koshen H.I.A. 2007. Strengths in Somali families. Marriage Fame Rev., 41: 71-99.

Koziol L.F., Budding D.E. \& Chidekel D. 2010. Adaptation, expertise, and giftedness: towards an understanding of cortical, subcortical, and cerebellar network contributions. Cerebellum, 9: 499-529.

Kuhn S.L. \& Stiner M.C. 2006. What's a mother to do? The division of labor among Neandertals 
and modern humans in Eurasia. Curr. Anthropol., 47: 953-980.

Lalueza-Fox C., Rosas A., Estalrrich A., Gigli E., Campos P.F., García-Tabernero A., GarcíaVargas S., Sánchez-Quinto F., Ramírez O., Civit S., Bastir M., Huguet R., Santamaría D., Gilbert M.T., Willerslev E. \& de la Rasilla M. 2011. Genetic evidence for patrilocal mating behavior among Neandertal groups. Proc. Natl. Acad. Sci. U.S.A., 108: 250-253.

Langergraber K.E., Siedel H., Mitani J.C., Wrangham R.W., Reynolds V., Hunt K. \& Vigilant L. 2007. The genetic signature of sexbiased migration in patrilocal chimpanzees and humans. PLoS ONE, 10: 1-7.

Lieberman D.E., Carlo J., Ponce de León M. \& Zollikofer C.P.E. 2007. A geometric morphometric analysis of heterochrony in the cranium of chimpanzees and bonobos. J. Hum. Evol., 52: 647-662.

Lieberman D.E., McBratney B.M. \& Krovitz G. 2002. The evolution and development of cranial form in H. sapiens. Proc. Natl. Acad. Sci. U.S.A., 99: 1134-1139.

Markarjan D.S., Isakov E.P. \& Kondakov G.I. 1974. Intergeneric hybrids of the lower (42 chromosomal) monkey species of the Sukhumi Monkey Colony. J. Hum. Evol., 3: 247-255.

Mason P.H. \& Short R.V. 2011. Neanderthal-human hybrids. Hypothesis, 9: 1-5.

Matsuzawa T. 2006. Sociocognitive development in chimpanzees: a synthesis of laboratory work and fieldwork. In T. Matsuzawa, M. Tomonaga \& M. Tanaka (eds): Cognitive Development in Chimpanzees, pp. 3-33. Springer-Verlag, Tokyo.

McKinney M.L. 2000. Evolving behavioral complexity by extending development. In S.T. Parker, J. Langer \& M.I. McKinney (eds): Biology, Brains, and Behavior: The Evolution of Human Development, pp. 25-40. School of American Research Press, Santa Fe.

Mellars P. \& French J.C. 2011. Tenfold population increase in Western Europe at the Neandertalto-modern human transition. Science, 333: 623-627.

Mellars P. 2004. Neandertals and the modern human colonization of Europe. Nature, 432: 461-465.
Mitani J.C. \& Watts D.P. 2005. Correlates of territorial boundary patrol behaviour in wild chimpanzees. Anim. Behav., 70: 1079-1086.

Mitani J.C., Watts D.P. \& Amsler S.J. 2010. Lethal intergroup aggression leads to territorial expansion in wild chimpanzees. Curr. Biol., 20: R507-R508.

Mitteroecker P., Gunz P. \& Bookstein F.L. 2005. Heterochrony and geometric morphometrics: a comparison of cranial growth in Pan paniscus versus Pan troglodytes. Evol. Dev., 7: 244-258.

Neves A.G.M. \& Serva M. 2012. Extremely rare interbreeding events can explain Neanderthal DNA in living humans. PLoS ONE, 7: 1-10.

Nishida T. 2004. Lack of "group play" in wild chimpanzees. Pan African News, 11: 2-3.

Nishida T., Hosaka K., Nakamura M. \& Hamai M. 1995. A within-group gang attack on a young adult male chimpanzee: ostracism of an ill-mannered member? Primates, 36: 207-211.

Nosil P. 2012. Ecological speciation. Oxford University Press, Oxford.

Nystrom P. 1992. Mating Success of Hamadryas, Anubis, and Hybrid Male Baboons in a "Mixed" Social Group in the Awash National Park, Ethiopia. Ph.D. dissertation, Washington University.

Parish A.R. \& de Waal F.B.M. 2006. The other "closest living relative": how bonobos ( $\mathrm{Pan} p a$ niscus) challenge traditional assumptions about females, dominance, intra- and intersexual interactions, and hominid evolution. Ann. N.Y. Acad. Sci., 907: 97-113.

Paixão-Côrtes V.R., Viscardi L.H., Salzano F.M., Bortolini M.C. \& Hünemeier T. 2013. The cognitive ability of extinct hominins: bringing down the hierarchy using genomic evidences. Am. J. Hum. Biol., 25: 702-705.

Patterson N., Richter D.J., Gnerre S. Lander E.S. \& Reich D. 2006. Genetic evidence for complex speciation of humans and chimpanzees. Nature, 441: 1103-1108.

Pearce E., Stringer C. \& Dunbar R.I.M. 2013. New insights into differences in brain organization between Neandertals and anatomically modern humans. Proc. R. Soc. B, 280: 1-7.

Pettitt P.B. 2000. Neanderthal lifecycles: developmental and social phases in the lives of the last archaics. World Archaeol., 31: 351-366. 
Pinhasi R. Higham T.F.G., Golovanova L.V. \& Doronichev V.B. 2011. Revised age of late Neanderthal occupation and the end of the Middle Paleolithic in the northern Caucasus. Proc. Natl. Acad. Sci. U.S.A., 108: 8611-8616.

Ponce de León M.S., Golovanova L., Doronichev V., Romanova G., Akazawa T., Kondo O., Ishida H. \& Zollikofer C.P. 2008. Neanderthal brain size at birth provides insights into the evolution of human life history. Proc. Natl. Acad. Sci. U.S.A., 105: 13764-13768.

Prüfer K., Munch K., Hellmann I., Akagi K., Miller J.R., Walenz B. \& Pääbo S. 2012. The bonobo genome compared with the chimpanzee and human genomes. Nature, 486: 527-31.

Richards M., Harvati K., Grimes V., Smith C., Smith T., Hublin J.-J, Karkanas P. \& Panagopoulou E. 2008. Strontium isotope evidence of Neanderthal mobility at the site of Lakonis, Greece using laser-ablation PIMMS. J. Archaeol. Sci., 35: 1251-1256.

Richards M.P., Trinkaus E. \& Klein R.G. 2009. Isotopic evidence for the diets of European Neanderthals and early modern humans. Proc. Natl. Acad. Sci. U.S.A., 106: 16034-16039.

Richter J. 2001. For lack of a wise old man? Late Neanderthal land use patterns in the Altmühl River Valley, Southern Germany. In N. Conrad (ed): Middle Stone Age and Middle Palaeolithic Settlement Patterns, pp. 205-220. Kerns Verlag, Tübingen.

Roebroeks W. \& Villa P. 2011. On the earliest evidence for habitual use of fire in Europe. Proc. Natl. Acad. Sci. U.S.A., 108: 5209-5214.

Rong R., Chandley A.C., Song J., McBeath S., Tan P.P., Bai Q. \& Speed R.M. 1988. A fertile mule and hinny in China. Cytogenet. Genome Res., 47: 134-139.

Rong R., Yang X., Cai H. \& Wei J. 1985. Fertile mule in China and her unusual foal. J. Roy. Soc. Med., 78: 821-825.

Rosati A.G., Stevens J.R., Hare B. \& Hauser M.D. 2007. The evolutionary origins of human patience: temporal preferences in chimpanzees, bonobos, and human adults. Curr. Biol., 17: 1663-1668.

Sánchez-Quinto F., Botigué L.R., Civit S., Arenas C., Ávila-Arcos M.C., Bustamante C.D. \&
Lalueza-Fox C. 2012. North African populations carry the signature of admixture with Neandertals. PLoS ONE, 7: 1-6.

Sankararaman S., Patterson N., Li H., Pääbo S. \& Reich D. 2012. The date of interbreeding between Neandertals and modern humans. PLoS Genet., 8: 1-9.

Santamaria D., Fortea J., de la Rasilla M., Martínez L., Martínez E., Cañaveras J. C., Sánchez-Moral S., Rosas A., Estalrrich A., García-Tabernero A. \& Lalueza-Fox C. 2010. The technological and typological behaviour of a Neanderthal group from El Sidrón cave (Asturias, Spain). Oxford J. Archaeol., 29: 119-148.

Schillaci M.A. \& Froehlich J.W. 2001. Nonhuman primate hybridization and the taxonomic status of Neanderthals. Am. J. Phys. Anthropol., 115: 157-166.

Schlanger N. 1996. Understanding Levallois: lithic technology and cognitive archaeology. Camb. Archaeol. J., 6: 231-254.

Schlesinger M. 2008. Heterochrony: It's (all) about time! In M. Schlesinger, L. Berthouze \& C. Balkenius (eds): Proceedings of the Eighth International Workshop on Epigenetic Robotics: Modeling Cognitive Development in Robotic Systems, pp. 111-117. Lund University Cognitive Studies, Lund.

Shea B.T. 1983a. Allometry and heterochrony in the African apes. Am. J. Phys. Anthropol., 62: 275-289.

Shea B.T. 1983b. Paedomorphosis and neoteny in the Pygmy Chimpanzee. Science, New Series, 222: 521-522.

Sherrow H.M. \& Amsler S.J. 2007. New intercommunity infanticides by the chimpanzees of Ngogo, Kibale National Park, Uganda. Int. J. Primatol., 28: 9-22.

Silk J.B. 2005. The evolution of cooperation in primate groups. In H. Gintis, S. Bowles, R. Boyd \& E. Fehr (eds): Moral Sentiments and Material Interests: On the Foundations of Cooperation in Economic Life, pp. 43-74. Massachusetts Institute of Technology, Cambridge.

Smith T.M., Tafforeau P, Reid D.J., Pouech J., Lazzari V., Zermeno J.P., Guatelli-Steinberg D., Olejniczak A.J., Hoffman A., Radovcic 
J., Makaremi M., Toussaint M., Stringer C. \& Hublin J.-J. 2010. Dental evidence for ontogenetic differences between modern humans and Neanderthals. Proc. Natl. Acad. Sci. U.S.A., 107: 20923-20928.

Spikins P.A., Rutherford H.E. \& Needham A.P. 2010. From homininity to humanity: Compassion from the earliest archaics to modern humans. Time and Mind, 3: 303-325.

Spinapolice E.E. 2012. Raw material economy in Salento (Apulia, Italy): new perspectives on Neanderthal mobility patterns. J. Archaeol. Sci., 39: 680-689.

Stevison L.S. \& Kohn M.H. 2009. Divergence population genetic analysis of hybridization between rhesus and cynomolgus macaques. Mol. Ecol., 18: 2457-2475.

Stewart J.R. 2005. The ecology and adaptation of Neanderthals during the non-analogue environment of Oxygen Isotope Stage3. Quatern. Int., 137: 35-46.

Striedter G.F. 2005. Principles of brain evolution. Sinauer Associates, Sunderland, MA.

Strier K.B. 2004. Patrilineal kinship and primate behavior. In B. Chapais \& C. Berman (eds): Kinship and Behavior in Primates, pp. 177-199. Oxford University Press, Oxford.

Tattersall I. \& Schwartz J.H. 1999. Hominids and hybrids: the place of Neanderthals in human evolution. Proc. Natl. Acad. Sci. U.S.A., 96: 7117-7119.

Townsend S.W., Slocombe K.E., Thompson M.E. \& Zuberbühler K. 2007. Female-led infanticide in wild chimpanzees. Curr. Biol., 17: R355-R356.

Trinkaus E. 1995. Neanderthal mortality patterns. J. Archaeol. Sci., 22: 121-142.

Trinkaus E. 2011. Late Pleistocene adult mortality patterns and modern human establishment. Proc. Natl. Acad. Sci. U.S.A., 108: 1267-1271.

Tung J., Alberts S.C. \& Wray G.A. 2010. Evolutionary genetics in wild primates: combining genetic approaches with field studies of natural populations. Trends Genet., 26: 353-362.

Tung J., Charpentier M.J.E., Garfield D.A., Altmann J. \& Alberts S.C. 2008. Genetic evidence reveals temporal change in hybridization patterns in a wild baboon population. Mol. Ecol., 17: 1998-2011.

Vandervert L.R. 2009. The appearance of the child prodigy 10,000 years ago: an evolutionary and developmental explanation. J. Mind Behav., 30: $15-32$.

Vandervert L.R. 2011. The evolution of language: the cerebro-cerebellar blending of visual-spatial working memory with vocalizations. J. Mind Behav., 32: 317-331.

Vervaecke H. \& Van Elsacker L. 1992. Hybrids between common chimpanzees (Pan troglodytes) and pygmy chimpanzees (Pan paniscus) in captivity. Mammalia, 56: 667-669.

Vigilant L. \& Langergraber K.E. 2011. Inconclusive evidence for patrilocality in Neandertals. Proc. Natl. Acad. Sci. U.S.A., 108: E87.

Vilà C., Leonard J.A., Götherström A., Marklund S., Sandberg K., Lidén K., Wayne R.K. \& Ellegren H. 2001. Widespread origins of domestic horse lineages. Science, 291: 474-477.

Villa P. \& Soriano S. 2010. Hunting weapons of Neanderthals and early modern humans in South Africa: similarities and differences. J. Anthropol. Res., 66: 5-38.

Wall J.D., Lohmueller K.E. \& Plagnol V. 2009. Detecting ancient admixture and estimating demographic parameters in multiple human populations. Mol. Biol. Evol., 26: 1823-1827.

Weaver A.H. 2005. Reciprocal evolution of the cerebellum and neocortex in fossil humans. Proc. Natl. Acad. Sci. U.S.A., 102: 3576-3580.

Weber J.N., Peterson B.K. \& Hoekstra H.E. 2013. Discrete genetic modules are responsible for complex burrow evolution in Peromyscus mice. Nature, 493: 402-406.

Wegmann D. \& Excoffier L. 2010. Bayesian inference of the demographic history of chimpanzees. Mol. Biol. Evol., 27: 1425-1435.

Wiens J.J. 2004. What is speciation and how should we study it? Am. Nat., 163: 914-923.

Williams J.M., Oehlert G.W., Carlis J.V. \& Pusey A.E. 2004. Why do male chimpanzees defend a group range? Anim. Behav., 68: 523-532.

Williams J.M., Pusey A.E., Carlis J.V., Farm B.P. \& Goodall J. 2002. Female competition and male 
territorial behavior influence female chimpanzees' ranging patterns. Anim. Behav., 63: 347-360.

Wilson M.L., Hauser, M.D. \& Wrangham, R.W. 2001. Does participation in intergroup conflict depend on numerical assessment, range location, or rank for wild chimpanzees? Anim. Behav., 61: 1203-1216.

Won Y.J. \& Hey J. 2010. Divergence population genetics of chimpanzees. Mol. Biol. Evol., 22: 297-307.

Wood R.E., Barroso-Ruíz C., Caparrós M., Pardo J., Santos B.G. \& Higham T.F.G. 2013. Radiocarbon dating casts doubt on the late chronology of the Middle to Upper Palaeolithic transition in southern Iberia. Proc. Natl. Acad. Sci. U.S.A., 110: 2781-2786.

Wrangham R.W. \& Peterson D. 1996. Demonic males: apes and the origins of human violence. Houghton-Mifflin Co., New York.

Wu C.-I. 1992. A note on Haldane's rule: hybrid inviability versus hybrid sterility. Evolution, 46: 1584-1587.

Wynn T. \& Coolidge F.L. 2002. The role of working memory in skilled and conceptual thought. Behav. Brain Sci., 25: 703-704.

Wynn T. \& Coolidge F.L. 2004. The expert Neanderthal mind. J. Hum. Evol., 46: 467-487. Wynn T. \& Coolidge F.L. 2012. How to think like a Neandertal. Oxford University Press, Oxford.
Yang M., Malaspinas A.-S., Durand E.Y. \& Slatkin M. 2012. Ancient structure in Africa unlikely to explain Neanderthal and non-African genetic similarity. Mol. Biol. Evol., 29: 2987-2995.

Yotova V., Lefebvre J.-F., Moreau C., Gbeha E., Hovhannesyan K., Bourgeois S., Bédarida S., Azevedo L., Amorim A., Sarkisian T., Avogbe P.H., Chabi N., Dicko M.H., Kou' Santa Amouzou E.S., Sanni A., Roberts-Thomson J., Boettcher B., Scott R.J. \& Labuda D. 2011. An $\mathrm{X}$-linked haplotype of Neandertal origin is present among all non-African populations. Mol. Biol. Evol., 28: 1957-1962.

Zilhão J., Angelucci D.E., Badal-Garcia E., d'Errico F., Daniel F., Dayet L, Douka K., Higham T.F., Martínez-Sánchez M.J., MontesBernárdez R., Murcia-Mascarós S., PérezSirvent C., Roldán-García C., Vanhaeren M., Villaverde V., Wood R. \& Zapata J. 2010. Symbolic use of marine shells and mineral pigments by Iberian Neandertals. Proc. Natl. Acad. Sci. U.S.A., 107: 1023-1028.

Zinner D., Arnold M.L. \& Roos C. 2011. The strange blood: natural hybridization in primates. Evol. Anthropol., 20: 96-103.

Associate Editor, Emiliano Bruner 